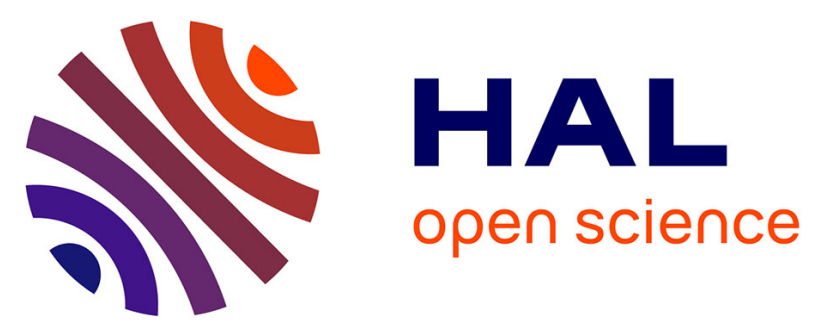

\title{
Conceptual Model of the Automated Decision-Making Process in Analysis of Emergency Situations on Railway Transport
}

Akbala Abuova, Valeriy Lakhno, Nurzhamal Oshanova, Bagdat Yagaliyeva, Andrew Anosov

\section{To cite this version:}

Akbala Abuova, Valeriy Lakhno, Nurzhamal Oshanova, Bagdat Yagaliyeva, Andrew Anosov. Conceptual Model of the Automated Decision-Making Process in Analysis of Emergency Situations on Railway Transport. 13th International Conference on Research and Practical Issues of Enterprise Information Systems (CONFENIS), Dec 2019, Prague, Czech Republic. pp.153-162, 10.1007/978-3030-37632-1_14. hal-03408628

\section{HAL Id: hal-03408628 \\ https://hal.inria.fr/hal-03408628}

Submitted on 29 Oct 2021

HAL is a multi-disciplinary open access archive for the deposit and dissemination of scientific research documents, whether they are published or not. The documents may come from teaching and research institutions in France or abroad, or from public or private research centers.
L'archive ouverte pluridisciplinaire HAL, est destinée au dépôt et à la diffusion de documents scientifiques de niveau recherche, publiés ou non, émanant des établissements d'enseignement et de recherche français ou étrangers, des laboratoires publics ou privés. 


\title{
Conceptual Model Of The Automated Decision-Making Process In Analysis Of Emergency Situations On Railway Transport
}

\author{
A.Abuova $^{1 \text { [0000-0002-8376-0501] }}$, V.Lakhno ${ }^{\text {[0000-0001-9695-4543] }}$, N.Oshanova ${ }^{3[0000-0003-4748-3821]}$, \\ B. Yagaliyeva ${ }^{4[0000-0003-4644-2261]}$, A.Anosov ${ }^{2[0000-0002-2973-6033]}$ \\ ${ }^{l}$ Kazakh University Ways of Communications, Almaty, Kazakhstan \\ ${ }^{2}$ National University of Life and Environmental Sciences of Ukraine, Kyiv,Ukraine \\ ${ }^{3}$ Abai Kazakh National Pedagogical University, Almaty, Kazakhstan \\ ${ }^{4}$ Yessenov University, Aktau, Kazakhstan \\ nurzhamal_o_t@mail.ru
}

\begin{abstract}
The article substantiates the need of the use of intelligent computer technologies in order to automate the process of analysis of emergency situations on the railway transport. There were considered the analysis variants with automatic generation of recommendations for managers for ES elimination in order to reduce time to develop and to make an informed decision. It is shown that during the analysis of emergencies on the railway transport a particular importance has the development of methods for creating decision support systems (DSS) based on the modeling of transient technogenic emergencies as a complex dynamic process taking into account cause and effect relationships. There is substantiated the necessity of the implementation of a modular software product for the intellectual analysis of emergency situations and the development of operational recommendations for managers on their liquidation. There was made the tasks detalization performed after the receipt of information on the development of the situation. On the basis of detailed tasks, there was created a conceptual model of the decision-making process. Developed a new formalized description of the model for the task of recognizing the situation and making primary decisions. The model differs from the known ones in that it takes into account the information dependencies of the situation parameters that are available to the decision maker. This makes it possible to formalize the decision-making process for recognizing and predicting a situation.
\end{abstract}

Keywords: decision support system, emergency situation analysis, automatic generation of recommendations, conceptual model

\section{The introduction}

Preparation, adoption and implementation of management decisions on the implementation of organizational and technical measures aimed at ensuring coordinated actions of structural units on emergency situations on railway transport with the aim of eliminating the consequences of an emergency for the shortest possible period of time is the main task of the operational headquarters. The operational headquarters of the 
enterprises of Kazakhstan Railways (KRT), associations, state enterprises, railway transportation directorates, institutions, organizations and structural units are created for direct management within their competence. Today railway transport control points (RTC), in fact, is the relevant situational centers for emergency response control and represent a hierarchical system, reflects the railway transport control structure. Actions of heterogeneous subdivisions of the functional subsystem of railway transport for the localization of dangerous situations and the elimination of their consequences are determined by significant complexity, which is due to the influence of diverse hazardous factors of such situations on people, equipment and the environment, as well as the complexity of organizing the management of these units in the difficult conditions of their work. The solution of such problems is impossible without the widespread use of computerized systems, including expert (ES) and decision support systems (DSS).

In order to automate the assessment of the situation resulting from the occurrence and development of emergencies, it is necessary to have a large amount of information about the nature of the development of emergencies in time and space, the status of special units and the results of their actions, provision with material and technical means, personal protective equipment, etc., and this amount of information is continuously growing with the development of the situation. In order to minimize the consequences of emergencies in the context of the rapid growth of information flows and lack of time, the need arises to create a clearly created system of automated operational information and analytical support for analyzing the situation, developing and making decisions on emergency response control with the widespread use of modern computer technology, information technology and DSS. Nowadays, control systems such as situational centers SC have entered the practice of managing complex dynamic multi-link systems [1].

At the same time, under the term center there is understood not only a specially equipped room, but also an appropriate information, telecommunication, software and methodological tools providing the process of information aggregation delivery in order to develop an appropriate solution.

All the above mentioned has led to the choice of the topic of our study, which involves the development of models and methods for constructing intellectualized (intellectual) DSSs for emergencies response on railways transport.

\section{$2 \quad$ Literature review}

Methods for solving control problems in emergency situations and mathematical models of the operational units functioning for its liquidation are considered in [1,2]. Particular attention was paid to the principles of construction and architecture of automated DSS during fire extinguishing [3, 4], to the aspects of creating an integrated expert and information DSS to eliminate chemical accidents, flood situations and forest fires [5], to the problems of decision support on identifying and eliminating emergency situations on the basis of dynamic expert systems (ES) [4], to the intellectualization of the decision support process in emergency situations at enterprises using information on the state of the environment [5-7]. But it should be noted that many publications [7-9] do not contain descriptive information related to the prediction of 
the emergencies development on railway transport in order to make recommendations to managers on the elimination of its consequences [9-11]. Meanwhile, not one of the analyzed works considers the use of specialized intellectualized DSS (IDSS) for the elimination of emergencies at railway transport facilities. The absence of such IDSS significantly complicates the process of analyzing the circumstances that have developed on the railway, increases the time period for making timely, informed decisions by the head of emergency response, which leads to an increase in losses from it.

The above mentioned necessitates reducing time to develop and to make an informed decision by the managers of the emergency response on the railway transport of technogenic nature due to the computerization of processes for identifying such situations.

\section{$3 \quad$ Aims and objectives of the research}

During the analysis of emergencies on the railway a particular importance has the development of methods for creating DSS based on the modeling of transient emergencies as a complex dynamic process taking into account cause-effect relationships. This is not possible without modern information technology.

In order to achieve this aim, it is necessary to develop a software product that consists of interconnected intelligent modules, and is able to perform an emergency analysis of emergency situations and to give recommendations for managers on their liquidation. In this case, it is necessary to create models for identifying emergencies and the process of developing recommendations for their elimination, taking into account the experience of experts and the requirements of managers [5]. The choice of an intelligent system for analyzing emergencies on the railway transport must be justified on the basis of a specific study of the subject area and on the knowledge of experts in solving such problems.

Therefore, the objectives of the study are: the development of a conceptual model of the decision-making process for assessing emergency situations on the railway transport and forecasting the development of the situation; the development of a formalized description of the model for the module of the designed DSS for the task of recognizing the situation and for automated decision-making.

\section{$4 \quad$ Methods and models}

In their daily professional activities, specialists involved in the elimination of the consequences of complex technogenic or other emergencies on the railway transport, including operational duty services (ODS), are dealing with the task of decisionmaking. Often the essence of these decisions is to generate possible alternatives, to evaluate them and to choose the best one. The choice of alternatives is based on a large number of conflicting requirements and on evaluating solution variants according to many criteria. The inconsistency of the requirements, the ambiguity of the assessment of the situation, the incompleteness and timeliness of the received information greatly complicate the adoption of the final decision and significantly affect its quality. 
Numerous researches $[3,5,6,8,10,11]$ show that a decision-maker (DM), without additional computerized support, uses simplified or contradictory decision rules. At the same time, decision-makers are guided only by their own experience and intuition, which as a result can lead to erroneous or inadequate solutions of situations.

Decision making support task is to provide decision-makers with the necessary information about the situation. In this case, it is necessary clearly to formalize the description of the input data processing processes. Today, DSS are a qualitatively new level of automation of decision-making processes in various areas of human activity $[1,3,4,8]$. They allow to organize intellectual support for the activities of the decision-maker and the ODS at making decisions, for example, in eliminating the consequences of emergencies on the railway transport. The introduction of DSS in the ODS activities on the railway transport would provide decision-makers with intellectual support for decision making and help in the following tasks: an automated support for the process of analyzing input data and supplementing it from various databases with information related to emergency response; a display of all information in an accessible and easy to read form; formation of an initial list of solution alternatives for a specific situation; creation of a situation model, assigning it to one of the well-known classes; prediction of the situation development in time, determination on the basis of this the consequences of primary alternatives; optimization of decisions related to the movement and placement of forces and means involved in emergency response on the railway transport. From the analysis of well-known DSS, it is clear that none of them is universal and cannot provide decision-makers with assistance in solving all the problems facing to them. Therefore, in order to provide intellectual support for decision-making by DM during emergency response on railways transport, the urgent task remains to develop a conceptual model of the decision-making process for assessing emergency situations on the railway transport and the prediction of the situation development, as well as formation of the model description for the module of the designed DSS (or IDSS) for the task of recognizing the situation and automated decision-making.

The development of reliable intelligent software is impossible without the use of high-quality and high-speed, dynamically changing databases and knowledge. At the same time, the input data are given by the vector of arguments containing general information about an emergency of technogenic character on the railway transport.

The knowledge base (KB) should contain generalized knowledge on emergency response (expert experience and regulatory rules), as well as knowledge about a real emergency. This knowledge is automatically found or generated from generalized knowledge (knowledge is presented in the form of fuzzy logical statements, production rules). The developed IDSS should have a unit for data and knowledge processing specific to a particular emergency in order to develop recommendations for its liquidation [2,4]. Management decisions are made using intelligent modules that use the knowledge base. Intelligent emergency analysis module is the main component of the system, and is able to automate the analysis process.

Based on an analysis of the headquarters activities dealing with the elimination of the consequences of emergency situations on the railway transport, as well as the analysis of previous researches $[3,7,11]$, there were completed the details of the tasks solved by the decision-maker (DM) after the receipt of information about the situa- 
tion. Based on detailed tasks, a conceptual model of the decision-making process was created.

In our opinion, as well as on the basis of the above analysis of previous researches in this field, the most optimal way to automate this process is to use production rules [1]. This will make it possible to create a flexible apparatus for calculating and providing recommendations on the recommended measures, forces and means in case of emergency response. This is especially true in situations where the system user will have a very small amount of input data. The results of the actions of the previous product can be used in the implementation of actions or conditions in the next product until the IDSS provides practical recommendations on the number of measures, forces and means for emergency response. In addition, the use of the production model of knowledge as a basic one allows decomposition of the analysis process. That is, to divide the task into simpler, functionally completed tasks. Therefore, the designed IDSS should have a modular structure, which will make it convenient to operate and will allow to scale new functional modules in its architecture.

Depending on the number of conditions and actions during the functioning of the system in order to eliminate conflict situations, the following types of rules are used: simple - one condition and one action; composed - many conditions and actions; branched - one condition and many actions.

An intelligent analysis involves the determination of emergency response parameters, based on the application of production rules with a postcondition and with the development of recommendations for emergency response.

In order to analyze the possibilities of DSS tasks fulfillment facing to the heads of services involved in the emergencies liquidation process on the railway transport, the tasks were formalized for the subsequent synthesis of models.

The situation place is characterized by the following parameters: $v_{1}-$ an indicator that determines the population density of the area (locality) in which an emergency occurred on the railway transport. The more crowded the place of emergency is, the more important is $v_{1} ; v_{2}$ - an indicator determining the presence of buildings, structures, institutions with an increased level of danger at the emergency site (factories working with hazardous substances, warehouses that store such substances, etc.). The value of $v_{2}$ depends on the hazard level of the structures and their quantity; $v_{3}-$ geographical location of the emergency place (for example, in the village). Therefore we will obtain: $V=\left\{v_{1}, v_{2}, v_{3}\right\}$.

Many events describing emergencies on the railway transport, we denote as $p$ : $p=\left\{p_{1}, \ldots, p_{a}\right\}, a=\overline{1, o}$, where $p_{a}-$ a single event that characterizes an emergency, $o-$ the total possible amount of events in the process of emergency development.

The time of an emergency occurrence (denoted as $C$ ) consists of two quantities: $C=\left\{c_{1}, c_{2}\right\}, c_{1}$ - the absolute time of an emergency occurrence, which is determined by the date and time of the emergency beginning, and $c_{2}$ - the relative time of the emergency, the period of time that has passed from the beginning of the emergency to the moment of receipt of a message about it. The absolute time of the situation relates 
to the amount of persons who may be participants or witnesses of the emergency and is described by two parameters: time of year $\left(c_{1,1}\right)$ and time of day $\left(c_{1,2}\right)$. In this way $c_{1}=\left\{c_{1,1}, c_{1,2}\right\}$.

The amount of persons who may be witnesses of emergencies is characterized by an indicator $K$ that depends on indicators $V, C$. The value $K$ increases with an increase of the possible amount of people. The status of the situation $S$ depends on its development, if $S \rightarrow \min$, then the situation is regular, and if $S \rightarrow \max$, the situation is emergency. We denote the set of situations types as $T=\left\{t_{1}, t_{2}, t_{3}, t_{4}\right\}$, where $t_{1}-$ is the indicator of the situation that determines the need to involve emergency brigades of railway, $t_{2}$ - IOC military personnel, $t_{3}$-immediate response groups (IRG) or investigative-operational groups (IOG), $t_{4}$ - the use of other actions not related to the involvement of the aforementioned forces and means. If it is necessary to attract a certain type of force, the value of the corresponding indicator increases, otherwise it decreases. The set of possible solutions for emergency response will be denoted as $R, R=\left\{r_{j}\right\}, j=\overline{1, q}, r_{j}-$ one of the possible solutions to a particular situation, $q$ - the total possible amount of solutions.

The formalized description of the model for the task of situation recognition and primary decisions making is described as follows:

$$
\begin{aligned}
& r_{j} \in R_{1} \text {, if } S \rightarrow \max \\
& r_{j} \in R_{2} \text {, if } t_{1} \rightarrow \max , S, t_{2}, t_{3}, t_{4} \rightarrow \min \\
& r_{j} \in R_{2} \cup R_{3} \text {, if } t_{1}, t_{2} \rightarrow \max , S, t_{3}, t_{4} \rightarrow \min \\
& r_{j} \in R_{2} \cup R_{4} \text {, if } t_{1}, t_{3} \rightarrow \max , S, t_{2}, t_{4} \rightarrow \min \\
& r_{j} \in R_{2} \cup R_{3} \cup R_{4}, \text { if } t_{1}, t_{2}, t_{3} \rightarrow \max , S, t_{4} \rightarrow \min \\
& r_{j} \in R_{5}, \text { if } t_{4} \rightarrow \max
\end{aligned}
$$

where $R_{1}$ - set of decisions on the recognition of an emergency situation; $R_{2}-$ set of decisions on the involvement of emergency brigades, $R_{2}=\left\{r_{2,1}, \ldots, r_{2, f}\right\}, f=\overline{1, h}$ where $r_{2, f}-$ decision on the involvement of appropriate emergency brigades, $h$ - maximum number of emergency brigades at the place where the decision-maker (DM) works; $R_{3}-$ many decisions on the involvement of IOC military personnel to eliminate emergencies on the railway. $R_{3}=\left\{r_{3,1}, \ldots, r_{3, e}\right\}, e=\overline{1, g}$, where $r_{3, e}-$ the decision to involve the appropri- 
ate detachment (group of detachments) of the IOC military personnel to eliminate the emergency situations on the railway, $g-$ the maximum amount of IOC military personnel for emergency response on railways in the area where the decision-maker works; $R_{4}$ - the decision to involve IRG or IOG, $R_{4}=\left\{r_{4,1}, r_{4,2}\right\}$, where $r_{4,1}-$ the decision to involve IRG, $r_{4,2}-$ the decision to involve IOG; $R_{5}$ - many decisions on recognizing a situation such that it does not require the involvement of additional forces and means, $R_{5}=\left\{r_{5}\right\}$.

As the situation development prediction we will consider the definition of the operational situation development in time, namely, how the place of the emergency and the events characterizing it will change.

The set of consequences of the chosen decision $N$ are: $N=\left\{n_{1}, n_{2}, n_{3}, n_{4}, n_{5}, n_{6}\right\}$ where $n_{1}-$ is the successful completion of the situation $\left(n_{1} \rightarrow \max \right)$ or vice versa $\left(n_{1} \rightarrow \min \right) ; n_{2}-$ the transition to a state of emergency ( $n_{2} \rightarrow \max$ ) or vice versa ( $\left.n_{2} \rightarrow \min \right) ; n_{3}-$ the sufficiency of the involved forces and means, if the involved forces and means are sufficient, then $n_{3} \rightarrow \max$, if it is necessary to attract additional forces then $n_{3} \rightarrow \min ,, n_{4}$ - losses from emergencies on the railway and human casualties $n_{4}=\left[n_{4,1}, n_{4,2}, n_{4,3}\right]$; where $n_{4,1}-$ is the amount of physical losses (casualties during the emergency on the railway), $n_{4,2}$ - the amount of material losses, $n_{4,3}$ - the amount of moral damage, with an increase in the amount of corresponding losses $n_{4,1}, n_{4,2}, n_{4,3} \rightarrow \max$, with a decrease $n_{4,1}, n_{4,2}, n_{4,3} \rightarrow \min ; n_{5}-$ possible amount of losses for the emergency response side on railway $n_{5}=\left\lfloor n_{5,1}, n_{5,2}\right\rfloor$, where $n_{5,1}-$ is the amount of physical losses among the personnel of the emergency response side, $n_{5,2}-$ the amount of material losses, with an increase in the amount of corresponding losses $n_{5,1}, n_{5,2} \rightarrow \max$, with a decrease $n_{5,1}, n_{5,2} \rightarrow \min ; n_{6}$ - time for which the situation can be resolved. The faster the situation is resolved, the less important is $n_{6}$. If the situation cannot be resolved successfully or it goes into a state of emergency $n_{6} \rightarrow \max$.

A formalized description of the model of the problem of predicting the development of the situation and determining the consequences of primary decisions is presented below. 


$$
\begin{aligned}
& \left.n_{1}=\left(\left(\left(p_{n_{1} w} \backslash p_{n_{1} u}\right) \backslash p_{s w}\right),\left(v_{3 n_{1} w} \backslash v_{3 n_{1} u}\right), v_{1}, v_{2}, c_{1,1}, c_{1,2}, c_{2}\right), r_{j}\right) ; \\
& n_{2}=\left(\left(p_{s w}, v_{2}, v_{1}, c_{1,1}, c_{1,2}\right), r_{j}\right) ; \\
& n_{3}=\left(\left(\left(p_{n_{3} w} \backslash p_{n_{3} u}\right),\left(v_{3 n_{3} w} \backslash v_{n_{3} u}\right)\right), r_{j}\right) ; \\
& n_{4}=\left(\left(\left(p_{n_{4} w} \backslash p_{n_{4} u}\right), v_{1}, c_{1,1}, c_{1,2}\right), r_{j}\right) ; \\
& n_{5}=\left(\left(p_{n_{5} w} \backslash p_{n_{5} u}\right), r_{j}\right) ; \underbrace{}_{6}=\left(\left(p_{s w}, v_{2}, v_{1}, c_{1,1}, c_{1,2}\right), r_{j}\right), i f v_{2}, v_{1}, c_{1,1}, c_{1,2} \rightarrow \max , c_{2} \rightarrow \min , p_{s_{w}} \neq 0 ; \\
& n_{6}=\left(\left(\left(p_{n_{1} u} \backslash p_{n_{1} w}\right),\left(v_{3 n_{1} u} \backslash v_{n_{1} w}\right), c_{2}\right), r_{j}\right), i f c_{2} \rightarrow \max ; p_{n_{1} u} \neq 0, v_{3 n_{1} u} \neq 0 ;
\end{aligned}
$$

where "\" - set difference; $p_{n_{1} w}, p_{n_{3} w}, p_{n_{4} w}, p_{n_{5} w}-$ events that during the decision $r_{j}$ contribute to the high value of the corresponding consequence; $p_{n_{1} u}, p_{n_{3} u}, p_{n_{4} u}, p_{n_{5} u}-$ events that during the decision $r_{j}$ do not contribute to the high value of the corresponding consequence; $p_{s, w}$ - events that during the decision $r_{j}$ contribute to the transition to emergency; $v_{3 n_{1} w}, v_{3 n_{3} w}-$ places that during the decision $r_{j}$ contribute to the high value of the corresponding consequence; $v_{3 n_{1} u}, v_{3 n_{3} u}-$ places that during the decision $r_{j}$ do not contribute to the high value of the corresponding consequence.

In order to solve the problems of recognition and assessment of the situation on the railway and primary decision-making on situation development prediction and the determination of the consequences of primary decisions there is proposed the use of the apparatus of artificial neural networks (ANN). The choice of ANN apparatus is motivated by the fact that the considered problems are weakly formalizable $[1,12-$ $14]$.

The architecture of the neural network consists of three layers of neurons.

Layer 1. The neurons outputs of this layer determine the degree of belonging of the input variables $x_{1}, x_{2}, \ldots, x_{7}$ to the corresponding sets with a trapezoidal membership function.

Layer 2. The neurons outputs are degrees of truth for each of the rules of the formalized model description. All layer neurons implement the OR operation.

Layer 3. The neurons of this layer are ordinary neurons that perform weighted additions. 
The input data vector $X$ contains 7 elements. That is, the neural network has 7 inputs: $x_{1}$-the geographical position of the emergency on the railway transport for emergency groups involved in emergency response; $x_{2}$ - the geographical position of the emergency on the railway transport for other groups involved in the emergency response; $x_{3}$-population at the emergency place on the railway transport; $x_{4}$-danger of the emergency place on the railway transport; $x_{5}$-absolute time of emergency occurrence on the railway transport; $x_{6}$-relative time of emergency on the railway transport; $x_{7}$-emergency events on the railway transport.

As a training sample there was used a sample of 1800 elements. From the results of training and testing, it follows that a neural network training using the back propagation algorithm of an error 'trainrp' allows to achieve one of the best accuracy in the least time. Therefore, in order to solve the problem of predicting the development of the situation and determining the consequences of the primary decisions, there was used an incompletely connected, direct-directed neural network, trained precisely by this algorithm. Initially, the training sample was prepared in MS Excel, and then imported into Matlab, for further network training.

Such tasks have a large amount of possible solutions, and their initial data may be inaccurate, erroneous, or inconsistent. Evaluation of the effectiveness of solutions will be considered the choice of the best solution among all possible. The formalized description of the model of the problem of evaluating the effectiveness of decisions is presented as follows:

$$
E_{r_{j}}=M\left(N_{s}, k_{s}\right),
$$

where $E_{r_{j}}$ - decision effectiveness $r_{j}, M$ - method by which an effective solution is sought; $N_{s}$ - consequences of possible solutions for the situation $s, s_{k}-$ a set of criteria for assessing the characteristics of a situation $s$, according to which the effectiveness of possible solutions is evaluated.

The indicated problem refers to the problems of multicriteria optimization, therefore, in order to solve it, it is advisable to apply the appropriate methods described in our previous researches. Based on the analysis of the activities of operational services involved in eliminating the consequences of emergencies on the railway transport, there was carried out the detalization of the tasks performed by them after the receipt of information about the situation. Based on detailed tasks, a conceptual model of the decision-making process was created.

\section{Discussion of results and prospects for further research}

There was developed a new formalized description of the model for the task of the situation recognition and primary decision-making. The model differs from the known ones in that it takes into account the information dependencies of the situation param- 
eters that are available to decision-makers at making decisions. This makes it possible to formalize the decision-making process for situation recognition and prediction.

A further prospect of work is the development of a method and model for solving problems of emergency recognition and prediction of its development, as well as primary decision-making based on fuzzy inference and fuzzy ANN, which uses information about the parameters characterizing the situation for automatically generation of many possible solutions.

\section{Conclusions}

there was substantiated the necessity of using intelligent computer technologies to automate the process of analyzing emergencies on railway transport with automatic generation of recommendations for managers (decision-makers) on their elimination in order to reduce the time to develop and to make an informed decision;

it was shown that at analyzing emergencies on the railway transport a particular importance has the development of methods for creating DSS based on the modeling of transient technogenic emergencies as a complex dynamic process taking into account cause and effect relationships;

there was substantiated the necessity of the implementation of a modular software product for intelligent analysis of emergencies and the development of operational recommendations for managers to eliminate them;

there was carried out the detalization of tasks performed by them after the receipt of information about the situation. Based on detailed tasks, a conceptual model of the decision-making process was created;

there was developed a new formalized description of the model for the task of situation recognition and primary decision-making. The model differs from the known ones in that it takes into account the information dependencies of the situation parameters that are available to decision-makers. This makes it possible to formalize the decision-making process for the situation recognition and prediction.

there was proposed a method for solving emergency recognition problems and predicting its development, as well as primary decision-making. The method differs from the known ones in that it is based on formalizing the description of the model of the corresponding problem and on the rules of fuzzy inference and fuzzy artificial neural network, which uses information about the parameters that characterize the situation in order to generate automatically many possible solutions.

\section{References}

1. Lakhno, V., Akhmetov, B., Korchenko, A.: Development of a decision support system based on expert evaluation for the situation center of transport cybersecurity, Journal of Theoretical and Applied Information Technology, Vol. 96, Iss. 14, pp. 4530-4540 (2018).

2. Ivashchenko, A.V.: Mul'tiagentnyye tekhnologii dlya razrabotki setetsentricheskikh sistem upravleniya //Izvestiya Yuzhnogo federal'nogo universiteta. Tekhnicheskiye nauki - T. 116. - №. 3 ( 2011) 
3. Gelovani, V.A., Bashlykov, A.A., Britkov, V.B., Vyazilov, Ye.D.: Intellektual'nyye sistemy podderzhki prinyatiya resheniy $\mathrm{v}$ neshtatnykh situatsiyakh $\mathrm{s}$ ispol'zovaniyem informatsii o sostoyanii prirodnoy sredy. M.: Editorial: 304, 3 (2001)

4. Kuznetsov, O. P.: Intellektualizatsiya podderzhki upravlyayushchikh resheniy i sozdaniye intellektual'nykh sistem //Problemy upravleniya.- №. 3(1) (2009)

5. Yamalov, I.: Modelirovaniye protsessov upravleniya i prinyatiya resheniy $\mathrm{v}$ usloviyakh chrezvychaynykh situatsiy. - Litres. (2014)

6. Shim, J. P., Warkentin, M., Courtney, J. F., Power, D. J., Sharda, R., Carlsson, C.: Past, present, and future of decision support technology. Decision support systems, 33(2), 111$126(2002)$

7. Medvedev, V. I., Teslenko, I. O., Kalinichenko, E. A.: New emergency cards for the prevention on liquidation of extreme situation with dangerous goods on the railway. In International Workshop on «Early warning and crises/disaster and emergency management. pp. 28-29 (2010)

8. Katsman, M., Kryvopishyn, O., Lapin, V.: Mathematical models of decision support system for the head of the firefighting department on railways. Reliability: Theory \& Applications, 6,3 (22) (2011)

9. Monoši, M., Ballay, M.: Analysis of risks and technical securing of rescue services at traffic accidents on railway crossing. Advances in Fire, Safety and Security Research 2014 i Editors note, 121 (2014)

10. János, B. E. N. Y. E.: The role of information of the population in elimination of accidents involving dangerous substances. Hadmérnök, 12(1) (2017)

11. Buts, Y.V., Kraynyuk, E.V., Kozodoy, D.S., Barbashin, V.V.: Evaluation of emergency events at the transportation of dangerous goods in the context of the technogenic load in regions. Science and Transport Progress. Bulletin of Dnipropetrovsk National University of Railway Transport, (3 (75)), 27-35 (2018)

12. Akhmetov, B., Lakhno, V.: System of decision support in weaklyformalized problems of transport cybersecurity ensuring, Journal of Theoretical and Applied Information Technology, Volume 96, Issue 8, pp. 2184-2196 (2018)

13. Akhmetov, B., Lakhno, V., Yerkeldessova, G.: Algorithm of parallel data processing in the automated dispatcherization system of railway transport movement, Journal of Theoretical and Applied Information Technology, Vol. 97, Iss. 9, pp. 2491-2502 (2019)

14. Akhmetov, B.: Methods and models of self-trained automated systems detecting the state of high-speed railway transport nodes, Journal of Theoretical and Applied Information Technology, Volume 97, Issue 9, pp. 2466-2479 (2019) 